Editorial 38.1

\title{
Art and empowerment
}

On a recent visit to Bethlehem my attention was caught by artworks on display at the Walled Off Hotel, founded by the artist Banksy. I was particularly interested in the exhibition by local Palestinian artists that were on show in the purpose-built galleries in the hotel. Mostly figurative paintings, the topics covered encompassed a wide range, dealing with issues from identity and trauma to more formal and aesthetic concerns. This was my first encounter with a show of painting from artists based in the West Bank, and I was struck with the vibrancy and energy evident in the exhibition, despite the prevailing difficulties that Bethlehem artists experience in attempting to maintain their practice. 


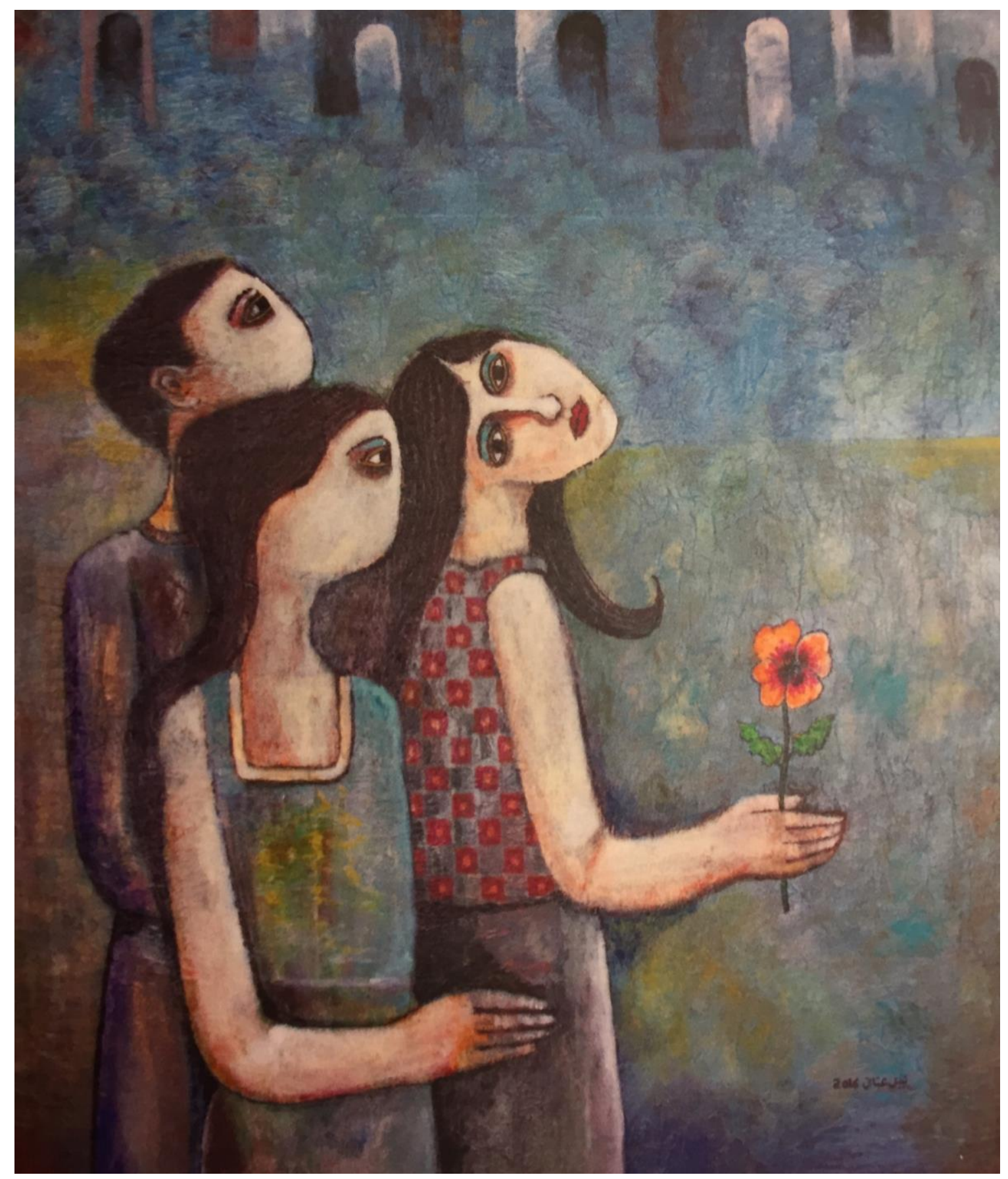

Figure 1. Nabil Anani: Nostalgia (c.2017), Walled Off Hotel gallery, Bethlehem

Unsurprisingly I saw works depicting the results of suffering brought about by trying to live a productive life while subject to obstructive and hostile governance. However, the sheer volume of work and the diversity of the subject matter were unexpected, and the energy evident in the determination to explore a wide range of artistic projects made an impression on me. Paintings, sculptures and craftworks on themes such as memory and nostalgia (fig 1), landscape and surreal imagination caught my 
attention. They were, like much interesting art, paradoxically both place-specific and generic: the topics directly emerging from singular and distinctive cultural and political situations, yet at the same time containing broader themes that resonate across international audiences.

As chance would have it, shortly after returning to the UK I had the opportunity to visit some Merseyside secondary school departments. I was delighted to see ample evidence of departments engaged in intense levels of production, and an abundance of commitment on the part of both students and staff. Remarkable things continue to happen in art departments in the UK. In one Liverpool school the walls and corridors throughout the school were painted with murals. These stretched the full length of the corridors, and filled one's vision as one entered them from classrooms along the way. The effect I found was powerful and uplifting, and testimony to this effect was the fact that, despite being busy corridors packed with young people, the walls remained undamaged and unspoiled. These large-scale works have continued over several years with large numbers of contributors from the school, students and dedicated staff. Again I was surprised to find that art departments can still thrive, despite years of austerity in England and Wales which have decimated school budgets and resources, exacerbated by an arbitrary hierarchy of subject disciplines which relegates the arts to a marginal position.

The juxtaposition of these events had unexpected consequences for me, and reminded me of Bob and Roberta Smith's argument (2014) that art 'gives a voice to the voiceless', referring to the way that his working class father had through his art abilities and interests became empowered and achieved considerable social mobility. From my experiences in these diverse places I sensed a similar notion of empowerment occurring in many of the works, at least during the moment of the creative act, The imaginative and provisional nature of the creative process that arises in the act of making, the 'how about this?' moment, as Bob and Roberta Smith puts it (2019), opens the potential for transformation, a picturing, sometimes literally, of how things might be other than they are.

Recently Bob and Roberta Smith (2019) has argued that the knowledge derived from creative practices is an essential aspect of learning, and therefore applies to all aspects of the education system. In particular he argues against elitist notions of art as a privileged activity for children in privately funded education. This is a great danger in the UK because of the marginalisation of the arts in mainstream state 
education, in contrast to the embracing of the arts by the privileged classes in private schools.

One refreshing aspect of my visits to these very different places was the evident similarity of the power of the works, both in their effect on the visitor as well as for the producers of the works. The vibrancy of the works in Liverpool were derived in part from the sheer volume of labour devoted to the works, and there was much evidence that staff had participated as artist teachers, producing works in some cases as intensely as the pupils. These works were imbued with the sheer graft of the participants' labour and commitment, assuming the role of artists taking control of the decision making for their practice in the school. The importance of art and culture in providing a platform for dissent - not necessarily the drum-beating political variety, but rather the low-key informal acts of creative adventure or non-conformity that permit the expression of ideas irrespective of obstructive regulatory policies, was abundantly evident, and seems as true on Merseyside as it does in Bethlehem.

\section{References}

Bob and Roberta Smith (2014) Art gives a voice to the voiceless: Bob and Roberta Smith at TEDxCourtauldInstitute (online). Available at:

https://www.youtube.com/watch?v=DpSOJZelYsQ (accessed 11 January 2019). Bob and Roberta Smith (2019) Untitled paper presented at the symposium of the National Arts Education Archive: Playful Cultural Encounters through Time event (unpublished). Tate Exchange, Tate Liverpool, 14 January. 